\title{
La Simbólica del Mal \\ de Paul Ricoeur comentada
}

\section{The Paul Ricoeur's symbolic \\ evil commented}

\section{Marie-France Begué}

Arquivo recebido em

12 de março de 2012

e aprovado em

10 de junho de 2012

V. $2-$ N. $3-2012$

**Doctora en Filosofía por

la Universidad del Salvador

(Buenos Aires-Argentina)

Filiación institucional:

Academia Nacional de

Ciencias de Buenos Aires,

Centro de Estudios Filosóficos,

Sección Fenomenología y

Hermenéutica y Facultad

de Filosofía y Letras de la

Universidad Católica Argentina.

Es miembro fundador, del

Círculo Latinoamericano de Fenomenología. Representante del Fonds Ricoeur para América Latina. Es miembro del Consejo de Redacción de la revista Communio Argentina.

\section{Resumen}

El presente trabajo recoge la exposición brindada por Marie-France Begué al SIPLET (Seminario Interdisciplinario Permanente Litera-tura, Estética y Teología) en torno a la Simbólica del mal de Paul Ricoeur. En él, se presenta la concepción de símbolo para Ricoeur, con sus dimensiones cósmica, onírica y poética, y la descripción fenomenológica que el autor hace del mal a partir de los símbolos de la mancha, el pecado y la culpa. El objetivo principal del texto fue brindar una introducción al pensamiento de Ricoeur en dicha obra a los participantes del seminario, en función del trabajo que ellos vienen realizando en torno al diálogo entre poesía y mística.

Palabras clave: Ricoeur, simbólica do mal, macha, pecado e culpa.

\section{Abstract}

This paper presents the exposure provided by Marie-France Begué to SIPLET (Permanent Interdisciplinary Seminar Literature, Aesthetics and Theology) around The Symbolism of Evil of Paul Ricoeur. In it, she presents Ricoeur's concept of symbol, with its cosmic, oneiric and poetic dimensions, 
and the phenomenological description that the author makes of evil and its symbols: stain, sin and guilt. The main objective of the paper is to provide an introduction to the thought of Ricoeur in this book to the seminar participants, according to the work they have been doing on the dialogue between poetry and mysticism.

Keywords: Ricoeur, symbolic evil, stain, sin and guilt.

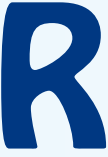

icoeur hace fenomenología-hermenéutica; no teología ni aún menos dogmática.

Su primera gran obra dedicada a la Filosofía de la Voluntad, se divide en dos partes:

La primera, eidética es decir que apunta a la esencia, lleva el nombre de Lo voluntario y lo involuntario (1950). Allí hace una descripción fenomenológica de la estructura del acto voluntario y de sus mecanismos. Para lograr esto, anuncia en su Introducción que dejará en suspenso dos problemáticas: La Trascendencia y el Mal, porque ambas están directamente ligadas al hombre empírico, con su existencia concreta, que somos cada uno de nosotros.

Recién en la segunda parte de su obra que se llama Finitud y culpabilidad (1960), describe la situación de este hombre tocado por la Trascendencia y por el Mal, es decir cuya voluntad puede ser buena o mala.

Quiere "sorprender en acto" (Ricoeur La Symbolique... 13) este paso de lo abstracto — la falibilidad como posibilidad del mal- a lo concreto de la falta. Ambas palabras son importantes: detrás del "sorprender" está la "sorpresa"; esta emoción —trabajada en VInos enseña que siempre hay algo de inesperado, de desconcertante en el surgimiento del mal. "En acto" significa en el momento mismo en que está sucediendo (en gerundio), en que se está dando el paso de lo abstracto a lo concreto. El "estarse dando" marca 
la entrada en el tiempo existencial de cada uno.

Aquí nos dedicamos solo a este último problema.

El punto de partida de Ricoeur consiste en que el mal es un desafío para la filosofía y para la teología (Le Mal 1986). Toda filosofía y teología que pretenda totalizar en un sistema, es decir, que pretenda responder racionalmente a todas las preguntas, fracasa ante el mal y el sufrimiento, como una ola contra la roca. El mal tiene algo irreductible y escandaloso para la razón especulativa. El problema de Dios y el problema del Mal no se agotan con nuestros razonamientos conformes a la no-contradicción y a totalizaciones sistemáticas.

Este fracaso puede desembocar en la tentación de abandonar dicho problema a la rebeldía o a la lamentación pasiva. Pero también podemos asumir críticamente nuestra pretensión racionalista e intentar "pensar de otra manera", capaz de soportar las contradicciones y el "in-acabamiento" — palabra clave en Ricoeur; la última de La memoria, la historia y el olvido_- propio de nuestra encarnación. Un pensar capaz de escuchar y asumir otros lenguajes como son los símbolos, las metáforas, los gestos, etc.

Intentamos acercarnos al problema del mal tal cual se nos presenta y tal cual se fue expresando a lo largo del tiempo, en los textos, los mitos y los ritos de las diferentes culturas.

"La tarea de pensar — sí, de pensar a Dios y de pensar el mal delante de Dios- puede no ser agotada por nuestros razonamientos conformes a la no-contradicción y a nuestra inclinación por la totalización sistemática”. (Ricoeur Le Mal 14)

La conciencia de sí, que es tan aguda en el sentimiento del mal, no dispone al comienzo de un lenguaje abstracto, sino de lenguajes muy concretos que le sirven espontáneamente para expresar sus vi- 
vencias. El hecho de la falta — la carencia, la quebradura - genera sentimientos plurales que se manifiestan simbólicamente mediante lenguajes también quebrados o indirectos como son la confesión, el mito o la elegía. Luego la especulación reflexionará sobre ellos; pero no hay que olvidar que dicha especulación es siempre secundaria y por lo tanto, cada vez menos expresiva de la vivencia. "Lo que se gana en claridad, se pierde en profundidad" (VI).

La confesión.

El mito y la elegía.

La especulación.

Siempre hay una circularidad entre ellos ${ }^{1}$.

Para alcanzar la "experiencia viva" aparece la necesidad de que en la fenomenología se "injerte" la hermenéutica.

1. "Llamo aquí fenomenología a la descripción de las significaciones implicadas en la experiencia en general, ya sea experiencia de los valores, de las personas etc., por lo tanto, una fenomenología de la confesión es la descripción de las significaciones y de las intenciones significadas, presentes en cierta actividad de lenguaje: la confesión". (Ricoeur Le conflit... 416-417).

La tarea del fenomenólogo es repetir la confesión del mal para desentrañar los diferentes puntos de vista. "Toda palabra puede y debe ser 'retomada' por el discurso filosófico". (Ricoeur La symbolique... 11).

Esto significa adoptar con simpatía y en imaginación, las motivaciones y las intenciones de la conciencia que confiesa. Sabemos que la confesión no es propiamente un acto filosófico, pero Ricoeur considera que está llamado a ser recogido por la filosofía, porque es una palabra que el hombre pronuncia acerca de sí-mismo. "Repetir" significa que el fenomenólogo no "siente" sino que "re-siente", al modo neutralizado _ al modo del "como si" _lo vivido por una conciencia que confiesa. Este trabajo de repetición aplicado ā las experiencias de mal, será entonces: "la explicitación, el desarrollo de las diversas capas de significaciones directas e indirectas que están confundidas en el mismo símbolo". (Ricoeur Le conflit... 418)

Esto es muy importante porque no se trata de simbiotizarse con el texto sino de entrar en diálogo, en un movimiento de pertenencia, de "fusión de horizontes"-diría Gadamer-, pero solo de horizontes y de distancia, para luego alcanzar la apropiación. Digo solo de horizontes porque cada vez sigo siendo yo, mi conciencia con su núcleo intencional, quien opera esta situación y la lleva al "buen puerto" de la comprensión y al "mal puerto" de la enajenación. 


\section{La confesión}

La confesión es la contrapartida o correlato -como dicen los fenomenólogos - de la vivencia que ella trae a la palabra.

La confesión se da en forma de narración cargada de imágenes simbólicas. Ella expresa, empuja hacia afuera la emoción, que de lo contrario "se cerraría sobre sí misma como una impresión del alma". (La symbolique... 15) Todavía no es confesión moral sino manifestación afectiva de una determinada vivencia. Esta vivencia tiene una triple característica: es vivencia de ceguera, de equivocidad y de escándalo.

"El penitente en su confesión expresa una experiencia ciega: se siente prisionero de la ganga de las emociones, del temor y de la angustia" (15).

Esta vivencia es la que busca esclarecerse en un discurso. La conciencia de falta es llevada a la luz de la palabra por la confesión. Gracias a ella, el hombre sigue siendo palabra hasta en la vivencia misma de lo absurdo, de su propio sufrimiento y de su angustia.

Por otra parte, en vez de comunicar una vivencia simple como podríamos imaginarlo- la confesión expresa vivencias complejas, que tienen diferentes capas de profundidad.

"La culpabilidad, en tanto que sentimiento de indignidad del propio núcleo personal, es solo la punta que avanza de una experiencia radicalmente individualizada e interiorizada". (15)

Este sentimiento de indignidad o de miseria remite a su vez a otra vivencia, aún más arcaica y fundamental, que es la de "pecado". La experiencia de pecado en toda su amplitud desborda el "hacer" particular (ligado a lo moral) y engloba a todos los hom- 
bres, como "situación existencial real del hombre ante Dios" (15). Pecado entonces significa estar "en crisis con Dios", "separado de Dios".

P. Claudel define el pescado como "la complacencia sacrílega de mi diferencia con Dios".

F. Jalics lo señala como el aspecto más sombrío de la naturaleza humana que engloba las "tendencias negativas crónicas en nuestro interior" (Jalics 164). Sus raíces son tan profundas que a menudo se sustraen a nuestra conciencia y por lo tanto nos volvemos impotentes para alcanzarlo. Pecado es lo que nos separa de Dios y de los hombres, oculto en lo más profundo de nuestro ser.

Ricoeur observa que los mitos de la errancia o de la caída narran esta experiencia en la cual ya nos encontramos. Esta situación es la que el cristianismo llamó "pecado original”.

Pero a su vez, esta noción de pecado es la "corrección, incluso la revolución de una concepción todavía más arcaica de la falta que es la suciedad (souilliure) concebida como una mancha que infecta desde afuera" (Ricoeur La symbolique... 15).

Culpa, pecado, suciedad constituyen una "diversidad primitiva" dentro mismo de nuestra experiencia de lo malo: "el sentimiento entonces, no solo es emocional sino que también es equívoco, porque está cargado con diversas significaciones", las que reclaman nuevamente al lenguaje, ahora para ser interpretadas; reclaman "un lenguaje que las ayude a "esclarecer las crisis subterráneas que tiene la conciencia de falta" (15).

Este lenguaje se expresa especialmente en el estilo de la interrogación: ¿por qué? ¿por qué a mí? o ¿por qué yo?. La interrogación expresa no solo el dolor de la ceguera, sino también el sen- 
timiento de estar, cada uno, alienados en nosotros mismos y con el deseo imperioso de liberación. Nos volvemos incomprensibles para nosotros mismos porque tocamos el lado oscuro de nuestro corazón.

Paradójicamente, la interrogación conlleva la experiencia de la diferencia entre el yo que pregunta y el resto del mundo, como si esperara una respuesta de "otro", que es el preguntado, el cuestionado. En el padecer y sufrir el "yo" se siente más individualmente "yo" y simultáneamente aviva su deseo imperioso de referencia, de encuentro. El hecho de sentirse alienado "desde adentro", y en cierta manera aislado, lo lleva a la necesidad de vincularse con el "otro" —o lo otro — como alguien —o algo — que viene "de afuera" para liberarlo. Esta paradoja es parte del proceso de individuación que cada uno debe atravesar. Al mismo tiempo este proceso, por ser humano, impulsa la necesidad de relación, del "ser-en..." y del "ser-con...". (Ricoeur "Individu et..." 55-72).

Esta experiencia de alienación dentro de nosotros -que llamamos pecado o miseria (L'homme Faillible) — es la experiencia más desconcertante, sorprendente y escandalosa que se suscita en nosotros provocando preguntas e interrogantes. La "falta" es una vivencia de quebradura. Todas las culturas han inventado modalidades originales —langagière lenguajera? - de lenguaje para expresar o canalizar la quebradura y la contradicción.

Por otra parte, todo lenguaje tiene en su origen una base imaginaria; una inventiva y una fecundidad creadora que permiten canalizar la irrupción de sentimientos existenciales como es la falta. El lenguaje primitivo de la falta es un lenguaje cargado de imágenes - “imagé- (La symbolique... 16). 
"La literatura penitencial manifiesta una invención lingüística que jalona las irrupciones existenciales de la conciencia de falta". (Le conflit... 417)

Esta interrogación, junto con la angustia que provoca su oscuridad, es lo que buscan aplacar los mitos cuando cuentan "como todo comenzó". Es también la que está presente en las lamentaciones de todo tipo que producen géneros literarios como son los salmos, las elegías, las tragedias, los dramas, antes de que la elaboración filosófica los eleve a su rango explicativo.

Hay una verdadera poética confesional de la falta que produce sus símbolos y metáforas con una determinada significación, pero que a través de ellos se está queriendo decir otra cosa, se apunta una segunda significación. Este doble movimiento tiene la característica de ser un estímulo capaz de trasladar la energía de un estado interior a otro y constituye la base de toda liberación, incluso de la sublimación propia de la confesión.

Pero para captar este "paso" tenemos que mantenernos en el nivel intermedio entre la vivencia muda y la explicación abstracta; mantenernos en el camino hacia el logos sin haber llegado todavía a su culminación y escuchar lo que nos "da que pensar" (La symbolique... 26 ).

Todo forma una gran totalidad abierta, holística: el lenguaje elemental de la confesión, el lenguaje desarrollado del mito y el lenguaje elaborado de la gnosis y de la contra-gnosis, así como el de la especulación ya son todos, cada uno en su rango, lenguajes secundarios respecto de la vivencia misma de la falta, que busca "ser dicha" y necesita estos lenguajes para emerger configurándose. Se trata de un verdadero "círculo hermenéutico". 
"No existe una autonomía de la especulación y el propio mito ya es segundo; pero tampoco hay una conciencia inmediata de la falta que pueda ahorrarse estas elaboraciones segundas y terceras" (17)

Sin embargo, a menudo no soportamos el vacío de no tener respuesta y asimilamos "respuestas apresuradas" (16), como si el interrogado estuviera ausente o nos diera la espalda. Pero en realidad, solo se trata de silencio, un vacío de palabra que nos invita a "cavar más hondo". Porque el silencio sigue perteneciendo al Reino de la Palabra, aún la más inefable. (Zambrano 2004)

Por otra parte, Ricoeur señala que si queremos explorar la "experiencia viva" no debemos olvidar que esta experiencia "ya es abstracta, en tanto que ya fue separada de la totalidad de sentido global en la que fluía. Esto significa que la experiencia individualizada nunca es inmediata: ella no puede ser dicha si no es gracias a los símbolos primarios que preparan su recapitulación —repriseen el mito y en la especulación" (La symbolique... 17)

\section{Símbolo: Su estructura}

La definición de símbolo se ajusta a los criterios con que analicemos su intencionalidad.

En su estructura más arcaica, el símbolo es el medio por el cual se opera el paso de la vivencia a la palabra y de la palabra al discurso. No solo garantiza la traslación de un estado a otro de profundidad o claridad, sino que, por ser operativo, influye en esta misma traslación. Para explorar esta traslación, necesitamos detectar la amplitud y la diversidad de situaciones y momentos - de contextos- en que el símbolo emerge. Es la misma estructura ambivalente del símbolo la que se reviste con las diferentes figuras 
poéticas, retóricas, narrativas etc.

Desde el punto de vista energético, volvemos a decir que el símbolo es

"un estímulo capaz de trasladar la energía de un estado interior a otro". (Ricoeur "Le mal")

Desde el punto de vista semántico es el movimiento que va de un sentido primario o literal a un sentido segundario o latente; pero con la particularidad que este segundo sentido solo se lo puede alcanzar en la tensión analógica que se forma entre ambos. El sentido secundario o latente solo puede ser percibido a través de sentido primario o literal. "El símbolo es el movimiento del sentido primario que
nos hace participar del sentido latente y así nos asimila
con lo simbolizado sin que podamos dominar intelec-
tualmente la semejanza. En este sentido, el símbolo
da, es dador, porque es una intencionalidad primaria
que da de manera analógica un sentido secundario".
(La Symbolique... 23)

"Entiendo por símbolo un lenguaje que designa una cosa por vía indirecta, al designar otra cosa que ella apunta directamente". (Le conflit... 418)

Desde el punto de vista de la lógica simbólica, el símbolo es el máximo formalismo y por lo tanto está desligado de su contenido. Cada símbolo es fruto de una decisión arbitraria de conectar el signo con lo que él significa, sin importar su vínculo ontológico. Designa en vacío.

Desde el punto de vista antropológico, el símbolo poético o arcaico está esencialmente ligado y no se lo puede separar de su contenido. El vínculo entre su intención y lo simbolizado es de analogía. 


\begin{abstract}
"Siempre consideraré como símbolo, en un sentido más primitivo, las significaciones analógicas formadas espontánea e inmediatamente dadoras de sentido...así la souillure es análoga de la mancha, el pecado análogo de la desviación, la culpa análoga de la carga..." (La symbolique... 25)
\end{abstract}

Antes de estudiar entonces los simbolismos presentes en las confesiones del penitente de una cultura - puede ser la hebrea o la babilónica o cualquier otra- necesitamos remontarnos hasta las formas simbólicas más ingenuas, a través de las cuales el hombre busca vincularse con lo divino, es decir "lee lo sagrado". Esta formas simbólicas están ligadas a lo cósmico — son las hierofanías-, o a lo nocturno de las producciones oníricas o también a lo que alimenta las diferentes ejercitaciones de la creatividad poética.

Dimensión cósmica.

Dimensión psíquica.

Dimensión poética.

Estas tres dimensiones siempre están de alguna manera presentes en todo símbolo auténtico. Las tres tienen la misma estructura; pero se alejan de lo arcaico en la medida misma en que se acercan a la palabra.

Las tres son mediadoras de la experiencia religiosa.

Ricoeur insiste en que el aspecto reflexivo de los símbolos que vehiculan lo sagrado -expresados por ejemplo en los sentimientos de suciedad, de desviación, de errancia, de exilio o de pesosolo se pueden comprender en profundidad, si no se los separa del resto —o sea, si se mantienen ligadas estas tres funciones entre sí.

\title{
Función cósmica
}


El hombre lee lo sagrado sobre el mundo y en ciertos elementos o aspectos del mundo como son el cielo, la tierra, el agua, etc.

Un símbolo aislado no habla por sí mismo sino que remite a determinadas "manifestaciones del mundo" donde lo sagrado "se muestra", se expresa como un fragmento del cosmos. Son lo que llamamos —después de M. Eliade- las hierofanías: manifestaciones de lo sagrado, como formando parte de la totalidad del cosmos. Este fragmento —el fuego ardiendo, por ejemplo- al simbolizarse pierde su aspecto concreto, solamente finito y parcial, y se carga con las innumerables significaciones unificadoras que el hombre le atribuye, a partir de su propia búsqueda ligada a la cultura en la que está inmerso².

Al volverse símbolo, el objeto cósmico integra y unifica varias vivencias que resuenan en nuestras profundidades y que, gracias él, emergen configurando experiencia. Ambas situaciones se dan simultáneamente. Un solo "símbolo-cosa" tiene en potencia innumerables símbolos hablados, los que a su vez, se anudan en una manifestación organizada singular, que responde a una determinada "cosmovisión" cultural.

\begin{abstract}
"Ser símbolo para las realidades cósmicas (como la luna o el sol) es recoger en un nudo de presencia una maza de intenciones significativas que, antes de dar que pensar, dan que hablar; la manifestación simbólica como cosa es como la condensación de un discurso infinito; manifestación y significación son estrictamente contemporáneas y recíprocas; la concreción en la cosa es la contrapartida de la sobre-determinación de un sentido inagotable que se ramifica en lo económico, en lo ético y en lo político. Así, el símbolo-cosa es poder de
\end{abstract}

2. Para trabajar esta noción de "hierofanía" y esta función "unificadora" de la experiencia de lo sagrado, remitimos a M. Eliade. Tratado de historia de las religiones. Paris, 1949, p. 385. 
innumerables símbolos hablados, los que, a su vez, se ligan en una manifestación singular del cosmos". (La symbolique... 18)

Pero quien produce la simbolización es el ser humano con su desproporción finito-infinita, mediatizada por el ejercicio de su capacidad de construir lenguajes. El hombre vive toda su relación con el mundo en esta doble dimensión. Lo que no hay que olvidar, es que nuestros símbolos hablados que parecen ser "primarios" respecto de otros más elaborados, como los ritos, los mitos u otras narraciones, son símbolos que "ya están en vía de cortarse de sus raíces cósmicas, pertenecientes al simbolismo en general. El solo hecho de comenzar a independizarse para ligarse con determinadas significaciones culturales y postergar otras que tal vez no corresponden con ella, simultáneamente también las separa de la totalidad simbólica todavía indefinida.

Por ejemplo, el simbolismo de la suciedad vivido como una amenaza al ser del hombre, está inmerso en lo cósmico, ligado a lo que ensucia - como el barro o lo podrido-y a lo que saca la suciedad y por lo tanto aleja lo amenazador. El peligro para el alma que luego simbolizará la mancha, es primero vivencia de peligro en general para la vida nuestro ser entero. La experiencia "profana" - que nunca lo es totalmente en las culturas arcaicas- enseña que solo podemos estar en presencia de esas cosas prohibidas si no acercamos a ellas protegidos por ciertos ritos. El "tabou" es precisamente esta condición que adquieren ciertas cosas, personas o acciones de permanecer "aisladas" y "prohibidas" por el peligro que lleva su contacto.

"Entre lo ensuciado, lo consagrado y lo sagrado, las equivalencias y las correspondencias subterráneas son probablemente imborrables; las hierofanías, en tanto 
que esfera de realidad, son las que engendran el 'régimen ontológico' (Eliade, op.cit, p, 27) característico de lo sucio" (La symbolique... 19).

Esto explica que el simbolismo de la suciedad, por ser e más arcaico de todos y tener una frondosidad inagotable, mantenga siempre sus abundantes raíces arraigadas a la sacralización de lo cósmico. Ellas adhieren a todo lo que el hombre vive como insólito y terrorífico en el mundo, produciendo ese doble movimiento de atracción y repulsión propio de lo sagrado que R. Otto llamó lo "numinoso".

\section{Función psíquica}

La dimensión onírica es la que nos permite sorprender el paso de la "función cósmica "a la "función psíquica" de los simbolismos "más fundamentales y más estables" de la humanidad. Ella atestigua la correspondencia entre el orden cósmico y el orden psíquico. Esta dimensión nos permite comprender que el vínculo entre el ser del hombre y el ser de la Totalidad es la Vida por excelencia, en tanto que el ser del hombre tiene su arraigo en el Ser originario y originante de toda la Creación. Participamos del Ser como de una fiesta sobreabundante.

Para comprender a fondo este fenómeno tenemos que penetrar más hondo que las diferentes metafísicas o meta-psicologías y hundirnos en nuestros propios arcaísmos. No se trata de elegir sino de sumar. Esto significa que cada vez que nos sumergimos en nuestros arcaísmos particulares, también nos sumergimos en los de la humanidad entera. Nuestras arqueologías privadas (ya lo reconoció Freud y aún más Jung) hunden sus raíces en representaciones que son comunes a una determinada cultura y a su folklore, 
pero que, a través de éste, participan del folklore de la humanidad entera. Son los famosos arquetipos o los arcanos, representados en el tarot o de otra manera.

Esta doble "regresión" es a su vez el camino posible para descubrir nuevas posibilidades en y para nosotros mismos.

"Manifestar lo sagrado sobre lo cósmico y manifestarlo en la psiquis son la misma cosa". (20)

“La 'regresión' es la vía larga o desviada de la 'progresión' y de la exploración de nuestras potencialidades"3 (20)

Esta función del símbolo como jalón y como guía de nuestro propio "volvernos nosotros mismos", tiene que mantenerse vinculado y no se lo debe oponer a la función cósmica que acabamos de ver. Cosmos y Psyché son los dos polos de la misma "expresividad"; yo me expreso al expresar el mundo y exploro mi propia sacralidad al descifrar la del mundo" (20).

\section{Función poética}

"La estructura de la imagen poética es también la del sueño cuando éste saca de los jirones de nuestro pasado una profecía de nuestro devenir, y también de las hierofanías que manifiestan lo sagrado en el cielo y las aguas, la vegetación y las piedras". (21)

El símbolo poético atestigua la expresividad del lenguaje en "estado naciente". En poesía el símbolo es sorprendido en el momento mismo en que surge_o emerge_como lenguaje; la poesía

3. Ricoeur cita a Heinz Hartman, Ego Psycology and the problem of adaptation (1939), in D. Rappaport, Organisation and Pathology of Trought, Columbia University Press, 1951. 
sorprende al símbolo justo cuando se está organizándo como lenguaje. De ahí que Bachelard —en la Poétique de l'espace, Paris, 1957 (en Ricoeur La symbolique... 21) — diga que la poesía "pone al lenguaje en estado de emergencia". Ella "tira" el símbolo hacia su expresión "langagière", lenguajera o lenguaraz o lingüística, antes de que él sea recogido en una estabilidad hierática como son el mito o el rito — según lo muestran la historia de las religionesy también antes de que sea "descifrada" por las interpretaciones más o menos analíticas, "venidas de una infancia abolida" (20-21).

Para comprender bien esto, es importante distinguir la imaginación de la imagen. Si entendemos por imagen la función de "presentificar lo ausente", es decir, de aniquilar lo real mediante un "irreal figurado o de ficción", este irreal-ficticio se parece todavía demasiado a un "retrato" de la cosa que él remplaza y sigue demasiado dependiente de ella, en tanto que la des-realizó; como si fuera un procedimiento para "hacer presentes las cosas del mundo".

Pero la imagen poética está mucho más cerca del verbo - acción- que del retrato. Al ser "nombrada" ella nos pone "en el origen mismo de nuestro ser parlante"; ella "se vuelve un nuevo ser de nuestro propio lenguaje, que "nos expresa a nosotros mismos haciendo que no volvamos lo que ella expresa. En el momento de crear, el poeta es lo que produce.

No hay tres formas, entonces, incomunicables de símbolos, sino que la estructura de la imagen poética es también la del sueño, cada vez que éste extrae jirones de nuestro pasado y nos ofrece como profecías de nuestro porvenir y es también la misma estructura que las hierofanías que manifiestan lo sagrado en el agua, el cielo, la tierra, etc.

Pero Ricoeur insiste en que esta única estructura solo se puede alcanzar de manera indirecta, a través de aproximaciones cada vez más 
cercanas a la esencia del símbolo.

\section{Características:}

1- Los símbolos son signos, es decir, expresiones que comunican un sentido. Este sentido es declarado en una intención llevada por una palabra. La dimensión simbólica emerge siempre dentro de un universo de discurso que de algún modo tiene logos.

Los símbolos tienen como dos puntas, una apunta a la expresividad del hombre, a sus sentimientos, y la otra apunta al ser trascendente, a lo ontológico. "El símbolo da que pensar". Debemos detectar estas dos puntas aunque no podemos agotarlas.

Todo signo apunta a algo y vale por ese algo; su significación es transparente. Pero todo signo no es símbolo. El símbolo guarda en su apuntar una doble intencionalidad: la primera o literal responde a la función de signo, la segunda apunta a algo que es como la primera.

Por ej: La suciedad o lo impuro: $1^{\circ}$ nivel intencional: la mancha, el miasma, significan, son signo, de la suciedad o lo impuro. Pero esto no es suficiente. Aparece un $2^{\circ}$ nivel intencional: Esta mancha que significa lo impuro apunta a expresar algo que es- como la mancha y que habla de cierta situación del hombre respecto de lo sagrado que ha sido ensuciada.

2- Esta $2^{\circ}$ significación del símbolo es opaca; y cuanto más opaca es, tanto más profunda e inagotable.

Aquí, el autor muestra tres niveles de símbolos:

1.- Los símbolos de primer grado o símbolos propiamente dichos: las "cifras".

2.- Los símbolos de segundo grado o "narraciones" que ya están organizadas en un discurso y una acción, los mitos y los ritos. 
3.- Los símbolos de recapitulación o de reflexión.

El punto de partida entonces no son las expresiones más elaboradas (como es por ejemplo la noción de pecado original), sino las más arcaicas, las más oscuras e inarticuladas porque son las que están más cerca de la vivencia o también las narraciones primarias como los mitos.

Ricoeur define "mito" de varias maneras:

Mito: "Relatos tradicionales que narran acontecimientos que sucedieron en el origen del tiempo y que otorgan un apoyo de lenguaje a las acciones rituales". (Le conflit... 417)

\begin{abstract}
"Relato tradicional acerca de los acontecimientos que sucedieron en el origen de los tiempos y destinado a fundar la acción ritual de los hombres y de manera general, a instituir todas las formas de acción y de pensamiento mediante las cuales el hombre se comprende a sí mismo en su mundo". (La symbolique... 12-13)
\end{abstract}

"Como una especie de símbolo, como un símbolo desarrollado en forma de relato y articulado en un espacio y un tiempo que no se pueden coordinar con los de la historia y de la geografía según el método crítico". (25)

La función del mito hoy ya no es "explicativa" porque ya no podemos insertar su temporalidad en nuestra temporalidad, definitivamente marcada por la historia, no tampoco ubicar geográficamente los lugares míticos, en nuestras geografías secularizadas. Sin embargo el mito sigue teniendo una función exploradora clave: nos permite explorar y comprender lo que su simbolización nos muestra que es el vínculo entre el hombre y lo que él considera su Sagrado.

Pero para percibir todo esto hay que mantener la experiencia en su propio lenguaje. Una figura no habla por sí misma sino en función del lugar que ocupa dentro de la red de significaciones simbólicas que la envuelve. El mito reubica las vivencias del hom- 
bre en un todo cuya narración le otorga orientación y sentido.

Los símbolos son como las células de los mitos.

El mal: es por excelencia la experiencia crítica de lo sagrado; atestigua la amenaza de disolución del vínculo entre el hombre y su Sagrado y por eso resuena con tanta intensidad, cada vez que el hombre se siente dependiente respecto de fuerzas que él no domina.

Ricoeur dice que la noción de "mala voluntad" o libertad sierva, guarda un gran misterio: por un lado, por ser voluntad ella es operativa, ejercicio libre de una capacidad. Pero por otro, ella se encuentra con un ya ahí del mal —no histórico sino ontológico-que la cautiva —esta noción de cautiverio es típicamente simbólica- y la debilita hasta volverla impotente para lo que fue destinada que es el bien.

El misterio es que por un lado, nosotros comenzamos el mal, -hacemos que entre en el mundo. Pero lo comenzamos a partir de un ya ahí que nuestro nacimiento carga de misterio impenetrable. Esto significa que el mal no es una "situación límite", sino una estructura contingente que nos toca y nos habita. Aunque su perversión no alcanza nuestro fondo originario, sí alcanza las estructuras de nuestro corazón, que lo inclinan fuertemente.

Ricoeur sostiene que el mal es de orden histórico, y por lo tanto revocable.

Por eso reclama lo que él mismo llama una poética de la libertad que se mueva entre la justicia y el amor de manera creativa, para concretarse. Esta poiesis de la libertad encuentra en el cristianismo una fuente inagotable de energía y motivación para liberar el "fondo de bondad" que hay en cada uno. Significa también que 
hace falta una "gracia", algo que le venga "de afuera" — como vino el mal en un comienzo- para que nuestra libertad sea redimida. Esta "liberación del Don" exige que nos insertemos en un "orden simbólico", que nos permita operar las diferentes transmutaciones emocionales necesarias para alcanzarla.

\begin{abstract}
"Siempre hay irrupciones de bondad que nada permite ser previstas y que sin embargo surgen a pesar de todo. Yo creo que siempre es posible recurrir a ese fondo de bondad. Esa es mi convicción. Y quiero agregar también que esa es la lección de los poetas. Para mí, la palabra de los poetas está al servicio de esta poiesis de la bondad. Yo no estoy de acuerdo en este punto con la Reforma, y le agradezco a Kant el haberme arraigado en la convicción que descansa sobre la diferencia fundamental entre la aptitud originaria al bien y la inclinación al mal". (Ricoeur "Le mal")
\end{abstract}

\title{
Bibliografía:
}

Eliade, Mircea. Tratado de historia de las religiones. Paris, 1949

Jalics, F. Ejercicios de Contemplación. Bs. As.: S. Pablo, 2009.

Ricoeur, Paul. Le volontaire et l'involontaire. Paris: Aubier, 1950. Trad. cast.: Lo voluntario y lo involuntario, 2 tomos, Buenos Aires: Docencia, 1988.

----- Finitude et culpabilité, t I: L'homme Faillible. Paris: Aubier, 1960; t II: La symbolique du mal. Paris: Aubier, 1960. Trad. cast.: Finitud y culpabilidad. Madrid: Taurus, 1970.

----- "La symbolique du mal interpretée". En Le conflit des interprétations. Paris: Seuil, 1969. Trad. cast: El conflicto de las interpretaciones: $\mathrm{t} \mathrm{III:}$ Introducción a la simbólica del mal. Bs. As: Aurora, 1976.

------ Le Mal, Un défi à la téologie et à la philosophie, Besancon: Labor et Fides, 1986.

“ "Le mal», entretien avec Bernard Sichère». En La règle du jeu. 7 (1996), $\mathrm{n}^{\circ} 19$, mai, 88-105.

------ "Individu et identité personelle". En Sur l'individu. Paris: Seuil, 1987.

Zambrano, María. La confesión: Género literario. Madrid: Siruela, 2004. 


\section{Datos personales y CV brevis:}

Nombre y apellido: Marie-France Begué

Correo electrónico: mfbegue@arnet.com.ar

Títulos: Doctora en Filosofía por la Universidad del Salvador (Buenos Aires-Argentina)

Filiación institucional: Academia Nacional de Ciencias de Buenos Aires, Centro de Estudios Filosóficos, Sección Fenomenología y Hermenéutica y Facultad de Filosofía y Letras de la Universidad Católica Argentina. Es miembro fundador, del Círculo Latinoamericano de Fenomenología. Representante del Fonds Ricoeur para América Latina. Es miembro del Consejo de Redacción de la revista Communio Argentina.

Publicaciones: Paul Ricoeur: La poética del sí mismo, prólogo de Paul Ricoeur (Biblos: 2002). Ha publicado numerosos artículos dedicados al pensamiento de Ricoeur, de los cuales en los últimos años se destacan: "Antropología de la Fidelidad" en Communio, Revista Internacional de Cultura Católica, N³, Primavera 2007; "Venga a nosotros tu Reino", Communio, Revista Internacional de Cultura Católica, Año 14, №1, Otoño, 2007, "De la tolerancia al reconocimiento mutuo", en Tolerancia V.II, Interpretando la experiencia de la tolerancia, Lima, Fondo Editorial de la Universidad Católica del Perú en sus 90 años, 2007, 553-564; "Adiós y Gracias, Homenaje a Paul Ricoeur", en Communio, Edición Argentina, año 13, N², invierno 2006; "El Estatuto epistemológico del testimonio. Una manifestación diferente de la verdad," en Fenomenología por decir. Homenaje a P. Ricoeur, comp... Patricio Mena Malet, Universidad Hurtado, Santiago de Chile, 2006; "Creatividad y poética del sí-mismo", en Anattelei se levanta, Homenaje a P. Ricoeur, Centro de Estudios Filosóficos y Teológicos, Córdoba, Argentina. Año VIII, N¹5, junio 2006; "De la tolerancia al reconocimiento mutuo", en Strómata, Rev. de Filosofía y Teología, Universidad del Salvador San Miguel, Bs. As., Año LXI- N¹/2, Enero-Junio 2005, 153-164; "Experiencia de sí, experien- 
cia histórica y función narrativa" en Escritos de Filosofía, Buenos Aires, $2005, N^{\circ} 45$.

Cursos dictados: Ha dictado numerosos cursos de grado y postgrado sobre Antropología filosófica, Fenomenología y Hermenéutica en la Universidad Católica Argentina, en la Academia Nacional de Ciencias de Buenos Aires y en el Centro de Espiritualidad Santa María de Buenos Aires. 